\title{
Barragem e turismo na representação dos barqueiros atingidos pela UHE Estreito em Babaçulândia - Tocantins
}

\author{
Dam and tourism on behalf of boatmen hit by the UHE Estreito in Babaçulândia - Tocantins \\ Presa y turismo en nombre de marineros afectados por el UHE Estreito de Babaçulândia - Tocantins
}

Ana Daisy Araújo Zagallo

Universidade Federal do Tocantins (UFT), Brasil

DOI: https://doi.org/10.18472/cvt.19n1.2019.1429

Redalyc: http://www.redalyc.org/articulo.oa?

anadaisy@uft.edu.br

id $=115459473014$

Marina Hainzenreder Ertzogue
Universidade Federal do Tocantins (UFT), Brasil
marina@uft.edu.br

Recepção: 25 Abril 2017

Aprovação: 09 Novembro 2018

\section{Resumo:}

Este artigo aborda as representações sociais do turismo dos barqueiros de Babaçulândia (TO), município afetado pela Usina Hidrelétrica Estreito - UHEE, instalada no Rio Tocantins. O estudo, de natureza qualitativa, baseou-se nos pressupostos teóricometodológicos da Teoria das Representações Sociais de Serge Moscovici para subsidiar a discussão dos dados coletados por meio de conversas qualificadas. Diante das transformações que descaracterizaram a paisagem e o modo de vida ribeirinho, buscou-se compreender a importância e o significado do turismo para essa comunidade, nas representações desses barqueiros. O estudo mostra que para esse grupo de atingidos, antes da implantação da UHEE, o turismo sazonal desenvolvido nas praias temporárias do Rio Tocantins era sustentável, pois envolvia toda a cidade, gerando benefícios à comunidade em geral. Concluiu-se que no contexto dos efeitos gerados pela UHEE, as representações produzidas por esses atores sociais denotam um cenário de incertezas, revelando um horizonte de insustentabilidade socioambiental para essa comunidade amazônica.

Palavras-Chave: Barragem, Turismo, Sustentabilidade, Representação Social.

\section{Abstract:}

This article discusses the social representations of tourism of the boatmen of Babaçulândia (TO) and municipality affected by the hydroelectric power plant of Estreito - UHEE, installed on the Tocantins River. The study, qualitative in nature, based on theoretical-methodological assumptions of the theory of social representations of Serge Moscovici to support the discussion of the data collected by means of qualified conversations. On the transformations that discharacterized the landscape and Riverside life, sought to understand the importance and significance of the tourism to this community, in the representations of these boatmen. The study shows that for this group of affected, before deployment of seasonal tourism UHEE developed in temporary beaches of Rio Tocantins was sustainable, because it involved the whole town, generating benefits to the community at large. It was concluded that in the context of the effects generated by UHEE representations produced by these social actors denote a scenario of uncertainties, revealing a social and environmental unsustainability horizon for this community.

KEYWORDS: Dam, Tourism, Sustainability, Social Representation.

\section{Resumen:}

Este artículo aborda las representaciones sociales de turismo de los barqueros de Babaçulândia (TO) y municipio afectadas por la hidroeléctrica de Estreito - UHEE, instalado en el Río Tocantins. El estudio cualitativo en la naturaleza, basado en supuestos teóricos metodológicos de la teoría de las representaciones sociales de Serge Moscovici para apoyar la discusión de los datos recogidos por medio de conversaciones calificados. Las transformaciones que descaracterizaram el paisaje y la vida de Riverside, buscaba comprender la importancia y trascendencia del turismo para esta comunidad, en las representaciones de los barqueros. El estudio muestra que para este grupo de afectados, antes de la implementación del turismo estacional que UHEE desarrollado en temporales playas de Río Tocantins era sostenible, porque participa todo el pueblo, generando beneficios a la comunidad en general. Se concluyó que en el contexto de los efectos generados por UHEE representaciones producidas por estos actores sociales denotan una situación de incertidumbre, revelando un horizonte de insostenibilidad social y ambiental de esta comunidad. 
Palabras Clave: Presa, Turismo, Sostenibilidad, Representación social.

\section{INTRODUÇÃO}

Em que pese a profícua produção científica sobre os efeitos das hidrelétricas no Brasil, ainda são incipientes as investigações que abordam o turismo e suas representações sociais no contexto das barragens, notadamente no estado do Tocantins onde as concepções e práticas turísticas estão por se revelar aos diversos olhares acadêmicos que buscam ampliar o debate sobre a sustentabilidade turística em ambientes alterados por esses empreendimentos hidrelétricos.

Discutir a sustentabilidade do turismo em áreas de barragens inclui compreender como as transformações econômicas, políticas e socioambientais da implantação de uma hidrelétrica são percebidas pelos atingidos, produtores e reprodutores de representações sociais sobre o desenvolvimento local no contexto da produção energética nacional.

Nesse sentido, o estudo das representações sociais sobre a atividade turística compõe uma dimensão simbólica que escapa às tradicionais abordagens estritamente econômicas ou ambientais, contribuindo para o entendimento dos conflitos na construção do turismo sustentável, um modelo particularmente desafiador para uma localidade onde o atrativo turístico natural foi substituído pelo lago do reservatório.

Como tema passível de investigação, essas representações sociais se inserem no âmbito das questões relacionadas à política energética na Amazônia Legal, especificamente na região do médio Rio Tocantins, onde as condições de vida da população ribeirinha são visivelmente precárias e socioambientalmente frágeis para enfrentar os impactos decorrentes do modelo hidroenergético vigente. Nessa perspectiva, parte-se da seguinte questão: diante dos efeitos socioambientais impostos pela UHE de Estreito ao município de Babaçulândia (TO), como essa comunidade representa o turismo local?

Para responder a tal questionamento, definiram-se como campo e sujeitos da pesquisa, respectivamente, o município de Babaçulândia (TO) e seus barqueiros, tomados como representantes dessa comunidade que, assim como o poder público e a iniciativa privada, compõem um sistema de cooperação do qual depende o desenvolvimento turístico local.

Nesse contexto, embora seja técnica e cientificamente viável mensurar o grau de sustentabilidade do turismo em uma localidade, considerando que a literatura dispõe de diversos instrumentos para subsidiar estudos dessa natureza, a análise desse requisito em uma cidade atingida por barragem, onde a atividade se desenvolveu quase que intuitivamente com estrutura precária e totalmente dependente dos atrativos naturais, não pode ficar circunscrita ao sim e ao não das pesquisas quantitativas, pois seriam insuficientes para compreender os significados do turismo para esses atores sociais, diante das perdas materiais, territoriais e simbólicas impostas pela hidrelétrica.

\section{CARACTERIZAÇÃO DO ESTUDO}

Inserida na Amazônia Legal, a área deste estudo compreende o município de Babaçulândia, situado às margens do Rio Tocantins, na região norte do estado do Tocantins, distante $435 \mathrm{~km}$ da capital, Palmas. Ocupa uma área de $1.788 \mathrm{~km}^{2}$ abrigando 10.424 habitantes, sendo 4.929 na parte urbana e 5.495 na zona rural (TOCANTINS, 2015). A cidade encontra-se no perímetro do reservatório da Usina Hidrelétrica de Estreito - UHEE que inundou 14,3\% de seu território (CNEC, 2001), afetando a vida de inúmeras famílias dependentes da agricultura de subsistência, da pecuária, do extrativismo e do turismo sazonal nas praias formadas pelos bolsões de areia do Rio Tocantins nos meses de estiagem entre junho e setembro.

$\mathrm{Na}$ construção do corpus da pesquisa social, aos pesquisadores qualitativos interessam os modos que as pessoas se relacionam com os objetos no meio em que vivem e analisam essas relações pelas opiniões, atitudes, 
sentimentos, explicações, estereótipos, crenças, identidades, ideologias, discurso, cosmovisões, hábitos e práticas, ou seja, pelas representações sociais: relações particulares entre sujeito-objeto em um meio social, pois querem "[...] entender diferentes ambientes sociais no espaço social, tipificando estratos sociais e funções, ou combinações deles, juntamente com representações específicas” (BAUER; GASKELL, 2002, p. 57).

O corpus de análise das representações sociais baseia-se no conteúdo das transcrições das entrevistas individuais realizadas pelo pesquisador. Desse modo, na coleta dos dados, seguiram-se as proposições de Bauer e Gaskell (2002) que partem de um tópico guia para cobrir os temas centrais e os problemas da pesquisa, sintetizando as questóes do assunto e estimulando o entrevistado a expor suas ideias como em uma conversação.

A escolha dos barqueiros como sujeitos da pesquisa deu-se em razão da sua posição no campo social do estudo, pois representam um grupo social cujas atividades foram extintas depois da formação do lago da UHEE, portanto, considerados diretamente atingidos pela barragem. Assim, o que qualifica um grupo social como representativo na pesquisa social é seu reconhecimento pelo pesquisador.

Dos 42 barqueiros cadastrados que atuavam no transporte de turistas e mercadorias antes da extinção da praia, foram entrevistados todos os $16^{[1]}$ membros remanescentes da Associação dos Barqueiros de Babaçulândia - ABBTO, selecionados pelos critérios de permanência e acessibilidade. As entrevistas foram concedidas nas residências dos participantes, em datas e horários de suas conveniências, permitindo observar suas condições de vida e da produção dos relatos, de modo a compreender sob quais circunstâncias as representações estavam sendo elaboradas.

Para atender ao objetivo específico de conhecer as representações desses barqueiros sobre o turismo local, elaborou-se um roteiro de questões abertas respondidas em depoimentos individuais gravados, coletados por meio de entrevistas abertas em conversas qualificadas que foram concedidos à autora desta pesquisa entre março de 2015 e junho de 2016, sendo que a interpretação dos conteúdos dessas entrevistas baseou-se nos pressupostos teórico-metodológicos da Teoria das Representações Sociais de Serge Moscovici e seus adeptos.

As conversas qualificadas são consideradas “[...] um esforço no processo de democratização e nivelamento dos sujeitos envolvidos na construção coletiva do conhecimento" (CARDIN, 2009, p. 12). Tais conversas permitiram captar as impressóes desses atores sociais sobre um conjunto de informações pautadas em um tópico guia que englobava a vida antes e depois da barragem do Rio Tocantins, a inundação da Praia do Coco, o significado do turismo de praias e suas expectativas em relação ao aproveitamento turístico do lago, sintetizando as questões do assunto e estimulando o entrevistado a expor suas ideias como em uma conversação que contemplou o tema central da pesquisa, qual seja o turismo no município antes e depois da formação do lago da UHEE.

\section{CONCEITOS NORTEADORES}

A implantação de hidrelétricas compromete a sustentabilidade socioambiental e econômica das áreas atingidas por seus reservatórios, impondo restrições e até extinção de culturas, como a pesca, o extrativismo e a agricultura de subsistência, atividades diretamente relacionadas com os recursos naturais. "Em todo o mundo a grande barragem serve ao mesmo modelo de desenvolvimento. Nos mais diversos países, o grande projeto hídrico busca impor um mesmo padrão de apropriação e uso dos recursos naturais” (VAINER, 1997, p. 12).

Contudo, a geração de energia por meios hidráulicos tem se consolidado como alternativa economicamente viável, impulsionando investimentos em hidrelétricas pelo mundo e expressivamente no Brasil, que figura entre os 20 países em que predomina a dependência de fonte hídrica, geradora de $92 \%$ do consumo interno (BREGAGNOLI; ROTHMAN, 2014). Com $10 \%$ da capacidade de produção hidráulica mundial, o País investe no aproveitamento desse potencial, confirmando a tendência de expandir essa matriz, especialmente com a estimativa de que “[...] entre 2016-2020, deverão ser viabilizados cerca de 19 GW 
em projetos hidrelétricos. Desse total, 15,5 GW, ou seja, 82\% estarão situados na Região Norte do País" (TOLMASQUIM, 2012, p. 253).

A despeito da eficiência desse modelo "limpo", muitas são as controvérsias acerca da sua expansão na região amazônica, onde os ecossistemas estão vulneráveis aos efeitos desses empreendimentos que alteram significativamente o ambiente, interferindo nos fluxos dos rios, inundando extensas áreas de matas, destruindo fauna e flora e afetando a vida das populações ribeirinhas, tão indefesas quanto impotentes diante dos traumáticos deslocamentos compulsórios inerentes ao processo de instalação das usinas.

Becker (2012, p. 789) entende que “[...] a construção de uma ou outra grande hidrelétrica seja necessária para garantir a oferta de energia na escala nacional com uma fonte renovável, mas a sucessão de hidrelétricas em áreas florestais pouco povoadas e sem base econômica significativa não parece sensata [...]”, pois os problemas elencados não se restringem aos aspectos econômicos da geração em si, mas de tudo que envolve as construções desses megaempreendimentos.

Exemplo do alcance dos efeitos da produção hidroenergética é a desarticulação do turismo sazonal impulsionado pelas praias fluviais formadas nas vazantes dos rios amazônicos, fomentando o desenvolvimento local de pequenos municípios ribeirinhos. Um turismo sazonal que, embora amador em termos de planejamento e gestão, constitui, muitas vezes, o principal vetor de desenvolvimento socioeconômico para diversas localidades, tornando-se insustentável diante da descaracterização da paisagem e do modo de vida local.

Nesse sentido, a sustentabilidade seria um conceito-chave em uma reflexão sobre a relação entre hidrelétrica e turismo, pois em diferentes níveis de intervenção, esses setores são potenciais geradores de impactos socioambientais, bem como produtores de representações sociais nas comunidades em que se desenvolvem, pois como agentes transformadores da realidade local, afetam sobremaneira seu modus vivendi. Como reforça Körössy (2008. p. 58), "[...] ao mesmo tempo em que o turismo é capaz de trazer benefícios, sobretudo econômicos, para as localidades onde se desenvolve, também tem a capacidade de provocar consequências negativas nesses locais, principalmente do ponto de vista ecológico".

A ideia de sustentabilidade está intrinsecamente relacionada ao conceito de desenvolvimento sustentável, entendido como "[...] aquele que atende às necessidades do presente sem comprometer a possibilidade de as gerações futuras atenderem as suas próprias necessidades” (CMMAD, 1991, p. 46).

$\mathrm{Na}$ esteira do desenvolvimento sustentável, cuja filosofia questiona as práticas e políticas de produção e consumo contemporâneas, a construção de um modelo turístico pautado nos princípios da sustentabilidade enfrenta os desafios da complexa transição de uma cultura de degradação socioambiental para uma gestão ética e participativa.

Para a Organização Mundial do Turismo (OMT, 2003), o turismo sustentável seria um condutor para gerenciar todos os recursos, de modo que as demandas econômicas, sociais e estéticas sejam atendidas sem que se despreze a manutenção da integridade cultural, dos processos ecológicos, da diversidade biológica e dos sistemas que garantem a vida. Na trilha desse ideal e, em contraposição à massificação da atividade turística, a OMT incorpora o discurso da sustentabilidade e assume o turismo sustentável como sendo “[...] aquele ecologicamente suportável em longo prazo, economicamente viável, assim como ética e socialmente equitativo para as comunidades locais, exigindo integração ao meio ambiente natural, cultural e humano" (OMT, 1995). Assim, o objetivo do turismo sustentável é promover o equilíbrio entre a conservação dos recursos naturais e culturais, de modo a conciliar viabilidade econômica e equidade social, adotando uma postura ética na interação com as comunidades locais (HANAI, 2012).

Se o turismo sustentável busca combinar crescimento econômico e conservação ambiental, pressupondo valorização cultural e participação comunitária, o mesmo não se pode dizer da produção hidroenergética. Conquanto estejam previstas medidas compensatórias nos termos da legislação vigente, as ações de mitigação para os inúmeros impactos da instalação e operação de hidrelétricas mostram-se sempre aquém dos irreversíveis efeitos socioambientais causados às áreas atingidas, pois como pondera Müller (1995, p. 45), “[...] 
ainda que a geração hidrelétrica seja sustentável, algumas regiões atingidas para que ela fosse gerada tiveram, em lugar de desenvolvimento, retrocesso insustentável".

No aproveitamento dos lagos dos reservatórios o turismo é apontado como uma alternativa para mitigar os impactos das hidrelétricas, na perspectiva do uso múltiplo das águas. A Agência Nacional de Águas - ANA (2005) reconhece que embora o turismo associado aos recursos hídricos esteja crescendo significativamente no País, sua expansão depende da definição de políticas e estratégias de uso racional para que sua oferta seja viável à sociedade.

Os reservatórios foram histórica e prioritariamente projetados para gerar energia elétrica e passam a competir com as atividades de contato primário que o turismo propicia, como banho e prática de esportes náuticos, exigindo "[...] a necessidade de ações integradas entre os diversos setores usuários da água no âmbito da bacia hidrográfica para garantir a sustentabilidade socioambiental, bem como os usos múltiplos dos recursos hídricos" (ANA, 2005, p. 21).

Tendo em vista que a gestão dos recursos hídricos deve garantir os usos múltiplos das águas, há a necessidade de se definir adequadamente as condições de operação dos reservatórios, analisando para cada situação os benefícios e prejuízos locais, regionais e nacionais, compatibilizando sempre que possível os diversos usos da água já que não há ordem de prioridade definida na Lei para nenhum deles (ANA, 2005, p. 55).

É nesse vácuo que hidrelétrica e turismo entram em rota de colisão, especialmente na Amazônia, onde a presença maciça de UHEs tem provocado significativos efeitos socioambientais que geram tanto a resistência das comunidades atingidas quanto a crítica social e acadêmica, pois a grandiosidade da região é proporcional à vulnerabilidade de seus ecossistemas, produzindo representações.

Nas representações sociais do ambiente, sujeito e objeto são indissociáveis, de forma que um objeto não existe para si mesmo, mas em relação a um indivíduo ou grupo, sendo a interação sujeito-objeto que define o próprio objeto e, ao formar sua representação do objeto, o sujeito reelabora, de algum modo, seu sistema cognitivo, para adaptá-lo ao seu sistema de valores, intrinsecamente ligado a sua história e seu contexto social. No campo dos estudos ambientais, a análise das representações sociais possibilita a compreensão de como objetos do mundo material, social ou das ideias são entendidos e produzem conhecimentos para interpretar a realidade e orientar ações (POLLI, KUHNEN, 2011).

A complexidade das relações entre sociedade e ambiente aponta para a necessidade de adquirir novas formas de conhecimento, diferentes das científicas, capazes de dar conta da realidade socioambiental contemporânea, pois "[...] o ambiente não é apenas o mundo de fora, o entorno do ser e do ente, ou o que permanece fora de um sistema." (LEFF, 2009, p. 19-21).

Moscovici (2010) ressalta que a principal finalidade das representações sociais é transformar o estranho em familiar, ou seja, tornar conhecido algo externo às práticas do grupo social. São familiares os fatos sobre os quais as pessoas estão habituadas a se manifestar com segurança porque fazem parte do seu cotidiano e os não familiares são aqueles dos quais não têm opinião formada por falta de referências em suas práticas.

Então, para tornar o desconhecido em familiar, as representações dependem da articulação de dois processos: ancoragem a objetivação. A ancoragem permite tornar o desconhecido em familiar pela incorporação do elemento novo ao sistema de categorias funcionais já organizadas no pensamento dos indivíduos, ancorando-as nas referências preexistentes na memória, criando uma abstração. A objetivação transforma essa abstração em um conceito, algo quase real, existente no mundo físico.

Para Guareschi e Jovchelovich (1995), esses dois processos são mecanismos específicos para que as representações sociais estabeleçam mediações, captando o pensamento de um grupo ou comunidade a um nível quase físico, materializando a dimensão simbólica das representações na vida social.

Segundo Jodelet (2001), a Teoria das Representações Sociais fornece um conjunto de funções essenciais sistematicamente organizadas e articuladas que permitem analisar as opiniões e atitudes de indivíduos integrantes de grupos sociais específicos, sobre a realidade em que vivem e interpretam com base em seu conhecimento de mundo. A autora ressalta que embora as representações sociais sejam distintas do 
conhecimento científico, por sua essência de senso comum, elas se constituem em objeto de investigação legítimo, em razão de sua relevância na vida social e de sua capacidade de revelar processos cognitivos e interações sociais, atuando, desse modo, como uma categoria analítica no contexto da pesquisa social.

Nessa perspectiva, o estudo das representações sociais de um grupo de barqueiros atingidos por barragem sobre o turismo pode dimensionar o alcance dos efeitos de uma hidrelétrica, na medida em que projeta a relação sujeito-objeto na interação sociedade-ambiente.

Quanto à contribuição da análise dessas representações na discussão sobre hidrelétricas, entende-se que esse tipo de estudo pode agregar conhecimentos introduzindo uma reflexão sobre turismo sustentável na comunidade a partir de suas próprias representações, tornando o conceito familiar para ser internalizado e assimilado como base para uma ação. Para Moscovici (2010, p. 49), “[...] a representação constitui uma preparação para a ação, pois, além de guiar o comportamento, ela remodela e reconstitui os elementos do meio ambiente em que o comportamento deve se ligar".

Em relação aos meios de elaboração dessa representação, entende-se que sua delimitação possibilita esclarecer o sentido que os grupos conferem ao objeto representado, admitindo-se que toda representação parte de alguém, um sujeito social integrado em circunstâncias específicas de espaço e tempo que se projetam em um objeto. Jovchelovitch (1995, p. 81) ressalta que "[...] as representações sociais são uma estratégia desenvolvida por atores sociais para enfrentar a diversidade e a mobilidade de um mundo que, embora pertença a todos, transcende a cada um individualmente".

As representações podem ser comparadas a um diálogo social que envolve comunicação e discurso, pois, como reforça Wagner (2000), são atributos pessoais, estruturas de conhecimento individuais, compartilhadas nas crenças, imagens, metáforas e símbolos em um grupo, comunidade, sociedade ou cultura.

Moscovici (2010) entende que o indivíduo age de forma particular e incisiva para construir as representações sociais, formando grupos para agregar informações comuns sobre a realidade que se lhes apresenta. Para o autor, as representações sociais são uma resposta da coletividade às influências externas que ameaçam sua identidade coletiva. Jodelet (2001, p. 22) reforça que essa representação “[...] é uma forma de conhecimento, socialmente elaborada e partilhada, com um objetivo prático, e que contribui para a construção de uma realidade comum a um conjunto social".

Assim, as representações sociais devem ser discutidas além das fronteiras metodológicas das visões positivistas para que melhor sejam compreendidas as múltiplas dimensões dos comportamentos e atitudes da sociedade em relação ao ambiente.

\section{DO RIO AO LAGO: O CONTEXTO TURÍSTICO DE BABAÇULÂNDIA}

Às margens do Rio Tocantins desenvolveram-se diversos núcleos urbanos, como Porto Nacional, Miracema do Tocantins, Filadélfia, Babaçulândia e Tocantinópolis, no estado do Tocantins; e Carolina, Estreito, Porto Franco e Imperatriz, no estado do Maranhão, além de Marabá, no estado do Pará, entre outros, frutos da intensa navegação e consequente fixação de populações ao longo do Tocantins em seu período áureo. "O Rio Tocantins foi a principal via de transporte comercial de cargas, ao longo dos últimos séculos, na região" (GOMES, 2007, p. 19).

Muitas dessas cidades passaram a sobreviver da agricultura familiar e de subsistência, da pesca e da pecuária, tudo praticado conforme os fluxos do rio, influenciado pela sazonalidade climática. Com a intensificação do turismo no Brasil, a partir dos anos de 1980, essas localidades foram se consolidando como destinos turísticos de sol e praia.

A nova forma de apropriação do rio como fonte de lazer e turismo impulsionou sua ocupação, marcando o ritmo do desenvolvimento desses núcleos urbanos, tanto os de médio porte como Porto Nacional, Miracema do Tocantins e Tocantinópolis, no estado do Tocantins, e Estreito e Carolina no Maranhão, como outros pequenos municípios, como Peixe, Pedro Afonso, Filadélfia e Babaçulândia, no Tocantins. Esses municípios 
baseavam suas economias no turismo sazonal propiciado pela época de estiagem das águas do Rio Tocantins em cujo leito emergiam bancos de areia, praias prontas para o lazer que atraíam visitantes locais e turistas de diversas regiões do Brasil.

Com a construção de hidrelétricas ao longo do Rio Tocantins, esse cenário foi se tornando cada vez mais raro, transformando as relações das comunidades com o rio, bem como provocando o desaparecimento de costumes tradicionais como a cultura barqueira, típica do cotidiano ribeirinho, incorporada ao turismo das praias fluviais, cujo fluxo mantinha os barqueiros em atividade. Segundo Medeiros e Cormineiro (2014, p. 152), por mais de dois séculos, os rios Araguaia e Tocantins foram os portões de acesso à Amazônia cuja importância para a região não se restringia a ser via de comunicação e interesse econômico, significavam espaços de construção sociocultural em que "[...] os barqueiros se constituíram importantes representantes e tradutores das experiências de viver dos e pelos rios”.

[...] a vida às margens do Rio Tocantins possuía um ritmo próprio, passado de geração a geração, pautado nas formas de fazer e de ser dos ribeirinhos. Se desde o século XVI o Rio Tocantins funcionou esporadicamente como caminho para o interior, na conquista e ocupação do território, mais tarde, como solução para o 'isolamento' do sertão, como saída do interior para o litoral, atualmente sua importância se liga mais a questôes voltadas para o fornecimento de alimentos, de energia (pela construção de hidrelétricas), para o turismo, e num futuro próximo, novamente como meio de transporte por meio de hidrovias e eclusas (OLIVEIRA, 2008, p. 7).

No leito do Rio Tocantins operam atualmente sete usinas hidrelétricas. Em 12 de julho de 2002 o Consórcio Estreito Energia - Ceste, composto pelas empresas Suez Energy, Vale, Alcoa e Camargo Corrêa Energia, venceu a licitação para explorar o bem público no aproveitamento hidrelétrico de Estreito por 35 anos (ANEEL, 2013).

Considerado um dos maiores projetos de geração de energia do Brasil, a UHEE tem capacidade instalada de 1.087 MW com energia assegurada de 584,9 MW médios e investiu cerca de R \$ 3,6 bilhões na sua implantação, gerando aproximadamente 10.000 empregos diretos e 25.000 indiretos.

A UHEE foi a última usina a entrar em operação no Rio Tocantins. Instalada na divisa dos estados do Maranhão e Tocantins, seu reservatório ocupa $260,23 \mathrm{~km}$ de extensão, com $434 \mathrm{~km}^{2}$ de área inundada, atingindo cerca de 200 mil habitantes em 12 municípios, sendo Carolina e Estreito, no Maranhão, e Aguiarnópolis, Palmeiras do Tocantins, Darcinópolis, Babaçulândia, Filadélfia, Barra do Ouro, Palmeirante, Goiatins, Itapiratins e Tupiratins, no Tocantins (CNEC, 2001).

Para Magalhães Filho et al. (2012, p. 2), entre os diversos impactos da UHEE nesses municípios destacamse os referentes à atividade turística, especialmente nas cidades de Babaçulândia e Filadélfia, cujo fluxo de turistas incrementava os setores do comércio e de serviços nas temporadas de praia. "O turismo de verão de fato é uma atividade impulsionadora da economia dessas cidades. Porém, a implantação do reservatório implicou no desaparecimento de suas praias naturais, gerando grandes perdas à economia e ao bem-estar da população local".

Em Babaçulândia, embora tenham se desenvolvido culturas extrativistas e agropecuárias, a economia do município baseava-se no fluxo turístico das praias temporárias do Rio Tocantins, especialmente da Praia do Coco, situada à margem oposta da cidade, no estado do Maranhão que anualmente atraía turistas de todas as regiões do Brasil, muitos deles captados pelas agências de turismo de Araguaína (TO), polo econômico da Região Norte do País que fica a $60 \mathrm{~km}$ de Babaçulândia e possui infraestrutura com aeroporto, hospedagem e alimentação.

De acordo com o Ministério do Turismo (BRASIL, 2015), Babaçulândia integra o Programa de Regionalização do Turismo por situar-se na área do Vale dos Grandes Rios - Araguaia e Tocantins, caracterizando-se como destino do turismo de sol e praia no mapa das regióes turísticas do estado (TOCANTINS, 2015). 
Desde a construção da UHE de Estreito, essa comunidade tem vivenciado transformações ambientais, econômicas e sociais que alteraram significativamente sua relação com o rio, os modos de vivê-lo e percebêlo, especialmente com a extinção de seu principal atrativo turístico, a Praia do Coco.

Ao contrário do que preconizavam os empreendedores, ocorreu uma queda drástica na atividade turística das cidades atingidas pela UHEE, devido a problemas como a baixa qualidade da água, desequilíbrio ecológico e inadaptação da população à infraestrutura instalada (MAGALHÃES FILHO et al., 2012). Para os autores, a implantação da usina gerou para Babaçulândia, além de imensurável perda simbólica, danos financeiros superiores aos investimentos, comprometendo seu desenvolvimento socioeconômico.

$\mathrm{Na}$ nova configuração ambiental, a praia natural cedeu lugar ao lazer e à recreação proporcionados pelo lago, cuja orla urbanizada passou a ser um atrativo permanente da cidade, alterando a cultura turística da região. Uma mudança que desarticulou toda a rede de serviços indiretos que envolvia a comunidade.

\section{AS REPRESENTAÇÕES DOS BARQUEIROS}

O turismo desenvolvido nos municípios antes da instalação da UHE de Estreito ocorria de forma espontânea, não sendo resultado de um conjunto de ações ou estratégias formais planejadas entre poder público, iniciativa privada e comunidade, pois a demanda por esse turismo sazonal era motivada por uma cultura regional cujos hábitos de lazer estavam diretamente relacionados ao rio. Embora esses municípios possuam outros pontos potencialmente turísticos, como serras e cachoeiras, as praias temporárias eram os atrativos que os classificavam como lugares turísticos.

A sustentabilidade do turismo dependia dessa diversificação, pois os barqueiros exerciam outras funções na comunidade - pescadores, pequenos produtores rurais, comerciantes e até funcionários públicos que complementavam sua renda montando barracas nas praias. E não somente eles se beneficiavam dessa atividade, pois toda a cidade se preparava para receber os turistas que consumiam tudo o que se produzia na agricultura de vazante, utilizando os serviços de hospedagem, alimentação, transporte e estacionamentos disponibilizados em terrenos próximos ao local de saída dos barcos para as praias e ilhas. Moradores locais são unânimes em afirmar que os ganhos financeiros com a temporada de praias superavam as demais atividades que eram exercidas no restante do ano.

Só em você ter o rio ali, a praia para todo ano trabalhar. Todo ano vai ter praia, vou trabalhar, vou ganhar meu dinheiro, que a gente trabalhava praticamente, junho, começava em maio, junho, julho e um pedacinho de agosto, mas você ganhava o suficiente pra o ano todinho (J. C. M. S., Entrevista realizada em 27/03/2015).

Mas assim, sempre tinha porque as vazantes eram no verão né e já no inverno nós mexia com a roça, a gente num ficava sem. (C. A. S., Entrevista realizada em 27/03/2015).

Lá eu vendia o gelo que eu pegava, que eu só revendo. Eu pegava uma barcada hoje que era 120 barra, 130 e depois de amanhã eu tinha vendido tudo. Hoje eu pego essas 120, 130 barra e tem vezes que eu passo 22 dias pra vender elas aqui (M. G. B. M., Entrevista realizada em 27/03/2015).

Meu Deus, dava pra viver o ano todo e até mais se fosse possível, minha filha. Tinha final de semana que eu fazia 800 reais, 200, 300, 400. Era assim, minha fia. Agora aqui acabou, acabou, agora nem vender mais eu tô vendendo (D. P., Entrevista realizada em 27/03/2015).

O turismo desenvolvido em Babaçulândia caracterizava-se basicamente pelo atrativo natural da Praia do Coco, pois a cidade oferece pouca infraestrutura, com equipamentos e serviços elementares, sendo quase que inexistente o monitoramento da atividade, limitado ao controle da venda dos bilhetes da travessia de barco para a praia pela Prefeitura e pela Associação dos Barqueiros de Babaçulândia - ABBTO. Segundo o presidente da Associação,

Aí nós fizemos um levantamento do que a média que a gente ganhava por ano, com essa atividade. Uma projeção, fizemos dados concretos do que a gente ganhava porque a gente antes a travessia nossa aqui era, tava tudo anotadozinho, tem tudo anotado na prefeitura, porque a gente pagava um percentual. A maior parte ia pra prefeitura, entendeu? Dia de show, aí cobrava oito reais da passagem e só recebia um e meio, dois, entendeu? Assim mesmo, dava, ainda tinha que tirar pra 
associação, tirar pra prefeitura, ainda tinha despesa de combustível, do ajudante, de tudo, mas ainda sobrava, e era muito, não era pouco não. Muito assim, pra gente, o volume da gente era muito, né? Daí nós fizemos aquela projeção, tipo assim, se nós távamos ganhando uma média de, vamos dizer assim, dez mil reais por ano, né? (D. P. R., Entrevista realizada em $14 / 10 / 2015)$.

A sazonalidade que, em regra, prejudica clássicos destinos turísticos de sol e praia na baixa temporada, em Babaçulândia era sinônimo de diversificação econômica, já que permitia a manutenção de outras atividades, como a agricultura de subsistência, a pesca e o extrativismo.

As impressões da realidade do turismo local pelos sujeitos da pesquisa contam também uma história desse ambiente, reproduzindo imagens e códigos socioambientais que são constantemente criados e partilhados pela sociedade. Nessas representações, fica claro que as alterações no ambiente físico com a barragem do Rio Tocantins modificaram não só a paisagem e a dinâmica da cidade, mas a forma de perceber o ambiente e o turismo no novo cenário.

Há referências quanto à elevação exagerada dos preços de venda e aluguel de imóveis e de produtos de consumo, com a especulação em torno de um crescimento turístico pós-inundação da praia natural e o que relatam é o aumento do desemprego, o declínio econômico da cidade e a saída de inúmeras famílias em busca de melhores oportunidades de trabalho na região de Araguaína - TO ou mais distante, desarticulando as relações comunitárias, essenciais ao desenvolvimento do turismo sustentável.

No discurso dos entrevistados é possível identificar a ação dos principais processos das representações sociais: a ancoragem, evidente quando se expressam sobre o turismo, incorporando novas visões ao objeto, após vivenciarem a realidade imposta pela barragem; e a objetivação, essas visões materializadas nas falas dos sujeitos:

A atração turística que nós tinha era uma praia muito boa, praia natural. Essa a praia artificial que tem aí, praticamente, muito ruim, muito sem graça, não é boa não. $\mathrm{O}$ nosso turismo era muito melhor do que ficou hoje com a barragem (S. R. D., Entrevista realizada em 09/10/2015).

A vida quando nós trabalhava no rio, nós achava mais, como diz, 'rifrigelo', né? Trabalhava mais, mas recebia mais de renda, né? Com prazer, também. Hoje eu moro lá no assentamento, na terra, mas eu tô trabalhando de roça, sabe? Acho que teve impacto em todos e a cidade piorou (A. D. C., Entrevista realizada em 16/10/2015).

Para que se obtenha uma visão panorâmica das representações desse turismo, além desses mecanismos, há que considerar as dimensões das representações sociais que compreendem as percepções expressas nos conceitos, os significados atribuídos ao objeto da representação e as imagens representativas dele. Essas dimensões se referem à atitude, à informação e ao campo de representação. $\mathrm{Na}$ primeira, observa-se a orientação geral sobre o objeto representado, o posicionamento direto do sujeito em relação a ele e a expressão do juízo de valor, uma qualificação positiva, negativa ou neutra diante do tema. Sobre a atividade turística no lago, em comparação ao rio, prevalecem as impressões negativas:

Sim, eu convivia mais com a natureza porque o rio não era essa água morta, essa água que esquenta demais a cidade, tudo (A. C. F., Entrevista realizada em 14/10/2015).

O rio era de todos, mas esse lago aí é só deles. É só perseguição em cima da gente. Todo dia eles tão aqui. Não pode encostar na beira do lago, seu gado não pode beber no lago. Fiscalização deles mesmo, da empresa. Tem hora que a gente perde a paciência (M. P. S., Entrevista realizada em 09/10/2015).

Na dimensão de informação, nota-se que o conhecimento sobre o turismo está sempre associado à atividade produtiva, fonte de renda e de desenvolvimento econômico local, subsidiando a dimensão do campo da representação em que a imagem concretizada do turismo o define como símbolo de prosperidade e vetor de crescimento comprometido pela barragem.

Piorou porque acabou. Vamos dizer: porque com o turismo nós gerava a renda, as coisas pra atrair o turismo, né? Por exemplo, os turistas vinham por causa dos barcos, nós tínhamos a melancia, nós tinha o feijão, nós tinha a abóbora, nós tinha tudo. Então o turista vinha atrás do que nós produzimos e brincar (M. P. S., Entrevista realizada em 27/03/2015). 
Acho que piorou, no meu ponto de vista. Eu acho que a importância do turismo aqui pra nós era a principal fonte de renda de muita gente, nem só dos barqueiros, de menino que carregava mercadoria pra chegar no barco, de mototáxi que trazia muita gente, levava e trazia. Hoje praticamente tá todo mundo em outras funções (E. S. M., Entrevista realizada em $14 / 10 / 2015)$.

As representações sociais podem ser contraditórias. Ao mesmo tempo em que se afirma que o turismo "piorou" ou "acabou", acredita-se que é o melhor caminho para a recuperação socioeconômica do município, como se pode observar nesses relatos:

Hoje o que tinha que ser investido aqui para melhorar aqui tem que ser o turismo. Ou melhora com o turismo ou talvez com outra coisa não vai ter como, no 'pé' que tá agora (S. D., Entrevista realizada em 14/10/2015).

O turismo é importante pra Babaçulândia. Porque o turismo traz a felicidade, traz o dinheiro para a cidade. Babaçulândia se tornou uma cidade aberta pra o turismo, então ficou praticamente sem jeito pra criar outra fonte de desenvolvimento a não ser o turismo mesmo (D. P. R., Entrevista realizada em 14/10/2015).

Nas representações do ambiente, sujeito e objeto são indissociáveis, de forma que um objeto não existe para si mesmo, mas em relação a um indivíduo ou grupo, sendo a interação sujeito-objeto que define o próprio objeto e, ao formar sua representação do objeto, o sujeito reelabora, de algum modo, seu sistema cognitivo, para adaptá-lo ao seu sistema de valores, intrinsecamente ligado a sua história e seu contexto social. Nas representações, simultaneamente individuais e sociais, os discursos individuais refletem o pensamento do grupo social com o qual partilham as mesmas experiências, evidenciando uma generalização no modo coletivo de pensar um problema comum, caracterizando o poder das representações sociais na criação e recriação da realidade social.

Eu acho o seguinte: que sempre quando tem o turista dá uma sustentabilidade pra comunidade, traz informações, renda, benefício. Eu acho que é viável, é muito importante, mas ainda não é isso que tá acontecendo em Babaçulândia. Acho que tá faltando mais empenho dos empreendedores que causaram essa destruição aí, tem que ter uma compensação, penso assim, uma compensação pra que a gente possa real mente usufruir e ter frutos desse turismo que vem em Babaçulândia. Basicamente, pros mais necessitados, não, praticamente pra cidade toda, não. Tem alguns, a minoria, a maioria mesmo, não. Porque Babaçulândia se tornou uma cidade aberta pra o turismo, então ficou praticamente sem jeito pra criar outra fonte de desenvolvimento a não ser o turismo mesmo. Então teria que fomentar bastante o turismo mesmo e tirar proveito dele (D. P. R., Entrevista realizada em 14/10/2015).

Na visão dos barqueiros, a sustentabilidade do turismo está relacionada à capacidade de manutenção da atividade que, durante suas vidas sempre foi garantia de ganhos para a maioria, por isso eles acreditam no turismo como a solução para os problemas do município, e esperam reinserir-se na nova dinâmica do lago:

Olha, minha expectativa é voltar a trabalhar com barco, ter mais renda com barco, ou mais hoje ou mais amanhã a gente vai ter que estimular, pra tentar implantar esses passeios no lago, porque se começar a virar moda, isso aí, né. Pode ser um preço popular, a gente vai ver (A. P. O., Entrevista realizada em 27/03/2015).

Nesse contexto, a imagem do turismo como mitigador encontra eco na racionalidade intrínseca às forças que definem as ações para viabilizá-lo, ou seja, a presença constante do lago acena para as possibilidades de uso recreativo na prática de esportes náuticos e visitação da orla urbanizada pelo empreendedor, apoiado pelo poder público local. Afinal, uma vez criadas, as representações sociais adquirem vida própria, circulam, interagem, se atraem e se repelem, dando oportunidade ao nascimento de novas representações, enquanto as antigas desaparecem.

\section{CONSIDERAÇÕES FINAIS}

Desde a instalação da UHEE, os barqueiros de Babaçulândia - TO lutam para sobreviver sem a antiga Praia do Coco, um lugar temporário que representava um verdadeiro território turístico, que não só garantia o sustento de inúmeras famílias, mas conferia sentido a suas vidas, guiadas pela natureza das águas. 
Nessa perspectiva, conhecer suas representações contribuiu sobremaneira para compreender as atitudes e valores comunitários sobre o turismo nessa região que carece de uma nova história ambiental, pois como acredita um barqueiro: "Não tem como pensar em outra coisa. O turismo? O que significa o turismo? Turismo, como dizer, é trazer qualidade de vida para as pessoas" (M. P. S., Entrevista realizada em $09 / 10 / 2015)$.

Os discursos individuais refletem o pensamento do grupo social com o qual partilham as mesmas experiências, evidenciando uma generalização no modo coletivo de pensar um problema comum, o que caracteriza o poder das representações sociais na criação e transformação da realidade social.

O discurso de um barqueiro que atuava como protagonista na atividade turística local é significativo para revelar o sentido do turismo para essa comunidade, pois a impotência diante do processo de exclusão socioeconômica a que foi submetido projeta os discursos dos demais grupos sociais atingidos, sendo sua experiência pessoal compartilhada coletivamente.

Assim, o significado do turismo para os atingidos de Babaçulândia não pode ser compreendido em suas múltiplas dimensões sem as representações desse grupo de barqueiros que, ao passarem de agentes a excluídos, refletem as injustiças de uma política energética que precisa ser revista no caminho alternativo da diversificação de suas fontes.

Assim, diante da realidade imposta pelo lago da usina, agora principal atrativo turístico da cidade, a comunidade precisa encontrar um caminho para adaptar-se a essa nova modalidade de turismo que requer um esforço conjunto para se desenvolver nos moldes da sustentabilidade, um conceito que só faz sentido se construído em bases comunitárias.

Nesses termos, para que o turismo represente um agente mitigador nesse contexto pós-barragem, fazse urgente e necessário repensar as práticas realizadas localmente, pois para alcançar um desenvolvimento local pela atividade turística, é imprescindível que se envolva a comunidade na construção do lago como um lugar turístico, posto que a transformação socioambiental provocada pela UHE Estreito impõe um desafio ainda maior no sentido de aguçar a capacidade endógena dos moradores para promover uma revitalização do turismo, de modo que o padrão de qualidade dos produtos e serviços oferecidos aos visitantes também alcance a população local.

\section{REFERÊNCIAS}

AGÊNCIA NACIONAL DE ÁGUAS - ANA. Cadernos de recursos hídricos: turismo e o lazer e sua interface com o setor de recursos hídricos. Brasília, 2005.

AGÊNCIA NACIONAL DE ENERGIA ELÉTRICA - ANEEL. Banco de Informações de Geração - BIG: capacidade de geração do Brasil, 2013. Disponível em: http://www.aneel. gov.br/aplicacoes/capacidadebrasil/ capacidadebrasil.cfm. Acesso em: abr. 2017.

BAUER, M. W.; GASKELL, G. (Ed.). Pesquisa qualitativa com texto, imagem e som: um manual prático. Tradução de Pedrinho A. Guareschi. Petrópolis: Vozes, 2002.

BECKER, B. K. Reflexões sobre hidrelétricas na Amazônia: água, energia e desenvolvimento. Boletim do Museu Paraense Emílio Goeldi. Ciências Humanas, Belém, v. 7, n. 3, p. 783-790, set.-dez. 2012.

BRASIL. Ministério do Turismo - Mtur. Categorização dos municípios das regióes turísticas do mapa do turismo brasileiro. 2015. Disponível em: \&lt;http://www.turismo.gov.br/assuntos/8162-mapa-do-turismo-detocantins-mudae-agora-estado-tem-40-munic\%C3\%ADpios-com-voca\%C3\%A7\%C3\%A3otur \%C3\%ADstica.html. Acesso em: 24 ago. 2015.

BREGAGNOLI, N. de D. N.; ROTHMAN, F. D. Impactos socioculturais: os efeitos da Usina Hidrelétrica Cachoeira do Emboque em sua comunidade atingida. Revista Agrogeoambiental, Pouso Alegre/MG, v. 6, n. 1, abr. 2014.

CARDIN, E. G. História oral, conversas qualificadas e o mundo dos trabalhadores. História na Fronteira, Foz do Iguaçu, v. 2, n. 2, p. 7-21, jul./dez. 2009. 
CNEC ENGENHARIA S. A. Estudo de Impacto Ambiental e Relatório de Impacto Ambiental - EIA/Rima da Usina Hidrelétrica de Estreito. São Paulo, 2001.

COMISSÃO MUNDIAL SOBRE MEIO AMBIENTE E DESENVOLVIMENTO - CMMAD. Nosso futuro comum. 2. ed. Tradução de Our common future. Rio de Janeiro: Editora da FGV, 1991.

CONSÓRCIO ESTREITO ENERGIA - CESTE. Programas ambientais. Disponível em: http://www.uheestreito.com.br/ver_secao.php?session_id=85. Acesso em: ago. 2016.

GOMES, K. D. Caracterização socioeconômica e percepção dos pescadores do rio Tocantins imediatamente a jusante da barragem da UHE Lajeado. Dissertação (Mestrado) - Programa de Pós-Graduação em Ciências do Ambiente. Universidade Federal do Tocantins - UFT. Palmas, 2007.

GUARESCHI, P. A.; JOVCHELOVITCH, S. Textos em representações sociais. 11. Petrópolis: Vozes, 1995.

HANAI, F. Y. Desenvolvimento sustentável e sustentabilidade do turismo: conceitos, reflexões e perspectivas. In: Revista Brasileira de Gestão e Desenvolvimento Regional. v. 8, n. 1, p. 198-231, jan-abr/2012, Taubaté, SP, Brasil.

JODELET, D. Representações sociais: um domínio em expansão. In: Jodelet, D. (Ed.). Representações sociais. p. 17-44. Rio de Janeiro: UERJ, 2001.

JOVCHELOVITCH, S. Vivendo a vida com os outros: intersubjetividade, espaço público e representações sociais. In: GUARESCHI, P.; JOVCHELOVITCH, S. (Org.). Textos em representações sociais. Petrópolis: Vozes, 1995.

KÖRÖSSY, N. Do Turismo Predatório ao Turismo Sustentável: uma revisão sobre a origem e a consolidação do discurso da sustentabilidade na atividade turística. Caderno Virtual de Turismo. Rio de Janeiro, 2008.

LEFF, E. Complexidade, Racionalidade Ambiental e Diálogo de Saberes. Educação e Realidade, v. 34, n. 3, p. 17-24, set./dez., 2009.

MAGALHÃES FILHO, L. N. L. et al. Valoração de danos ambientais devido à implantação da UHE de Estreito: o caso de Babaçulândia - TO. Espaço Energia, n. 16, abril, 2012.

MEDEIROS, E. A.; CORMINEIRO, O. M. M. Barqueiros, navegação e cultura: narrativas e representações acerca da dominação e das resistências nas águas dos rios Araguaia e Tocantins entre os séculos XIX e XX. História Revista, v. 19, n. 3, p. 151-187. Goiânia, 2014.

MOSCOVICI, S. Representações Sociais: investigações em psicologia social. Trad. Pedrinho A. Guareschi. 7. ed. Petrópolis, RJ: Vozes, 2010.

MÜLLER, A. C. Hidrelétricas, meio ambiente e desenvolvimento. São Paulo: Makron Books, 1995.

OLIVEIRA, M. de F. Identidade nas margens do Rio Tocantins. In: XIII ENCONTRO DE HISTÓRIA ANPUH - RIO IDENTIDADES, 2008, Rio de Janeiro. Anais Eletrônicos... Rio de Janeiro: ANPUH - Associação Nacional de História Seção Rio de Janeiro. Disponível em: http://encontro2008.rj.anpuh.org/resources/content/ anais/1212956085_ARQUIVO_TextoIdentidadenasmargensdoRioTocantinsMariadeFatimaOliveiraXIIIEncontrodeHist Acesso em: 31 mai. 2016.

ORGANIZAÇÃO MUNDIAL DO TURISMO (OMT). Carta do Turismo Sustentável. OMT/Unesco. Espanha, 1995.

ORGANIZAÇĀO MUNDIAL DO TURISMO (OMT). Guia de desenvolvimento do turismo sustentável. Trad. Sandra Netz. Porto Alegre: Bookman, 2003.

ORGANIZAÇÃO MUNDIAL DO TURISMO (OMT). Introdução ao Turismo. São Paulo: Roca, 2001.

POLLI, G. M.; KUHNEN, A. Possibilidades de uso da teoria das representações sociais para os estudos pessoaambiente. Estudos de Psicologia. Natal, v. 16, n. 1, p. 57-64, abr. 2011.

TOCANTINS (Estado). Secretaria de Planejamento e Orçamento. Diretoria de Pesquisa e Informações Econômicas. Perfil socioeconômico dos municípios - Babaçulândia. Palmas - TO, 2015.

TOLMASQUIM, M. T. Perspectivas e planejamento do setor energético no Brasil. Estudos Avançados [on-line], v. 26, n.74, p. 247-260, 2012. 
VAINER, C. B. Como temos lutado e como continuaremos lutando contra as barragens. Texto base para discussão. In: I Encontro Internacional de Povos Atingidos por Barragens. Relatório. p. 11-15. Curitiba, 1997.

WAGNER, W. Sócio-gênese e características das representações sociais. In: MOREIRA, A. S. P.; OLIVEIRA, D. C. (Org.). Estudos interdisciplinares de representação social. p. 3-25, 2. ed. Goiânia: A. B., 2000.

\section{Notas}

[1] Para preservar a identidade dos sujeitos da pesquisa, os entrevistados citados neste texto foram identificados por suas iniciais.

\section{BY}

